\title{
Successful treatment of Gaucher disease type 1 by enzyme replacement therapy over a 10 -year duration in a Japanese pediatric patient: A case report
}

\author{
YUJI OTO $^{1}$, TAKESHI INOUE ${ }^{1}$, SO NAGAI ${ }^{1}$, SHINICHIRO TANAKA ${ }^{1}$, HISASHI ITABASHI ${ }^{1}$, \\ MASAHISA SHIRAISIHI ${ }^{1}$, AKIHISA NITTA ${ }^{1}$, NOBUYUKI MURAKAMI ${ }^{1}$, \\ HIROYUKI IDA $^{2}$ and TOMOYO MATSUBARA ${ }^{1}$
}

\author{
${ }^{1}$ Department of Pediatrics, Saitama Medical Center, Dokkyo Medical University, Koshigaya, Saitama 343-8555; \\ ${ }^{2}$ Department of Pediatrics, The Jikei University School of Medicine, Tokyo 105-8471, Japan
}

Received February 20, 2020; Accepted November 11, 2020

DOI: $10.3892 / \mathrm{etm} .2021 .9677$

\begin{abstract}
The prevalence of Gaucher disease (GD) in Japan is much lower than that in Western countries; therefore, data on Japanese pediatric patients with GD type 1 are currently limited. The present study reports on the case of a Japanese pediatric patient with GD type 1 who was diagnosed when she presented with hepatosplenomegaly, thrombocytopenia and slight anemia at the age of 2 years. Serology tests revealed high levels of acid phosphatase (ACP) and angiotensin-converting enzyme (ACE). A bone marrow biopsy revealed the presence of Gaucher cells. Abdominal MRI indicated huge hepatosplenomegaly. Erlenmeyer flask deformity was observed on X-ray examination. MRI of the femora featured a high-intensity area within the diaphysis region. The enzymatic activity of leukocyte $\beta$-glucosidase, the measurement of which is necessary for a definitive diagnosis of GD, had decreased to $186.7 \mathrm{nmol} / \mathrm{h} / \mathrm{mg}$ (reference range, $1,424.0-2,338.0 \mathrm{nmol} / \mathrm{h} / \mathrm{mg}$ ). Based on these results, the patient was clinically diagnosed with GD. Glucocerebrosidase gene analysis identified the compound heterozygote mutation of F213I (c.754T >A) on exon 7 and L444P $(\mathrm{c} .1448 \mathrm{~T}>\mathrm{C})$ on exon 11. Enzyme replacement therapy (ERT) along with an intravenous infusion of $60 \mathrm{U} / \mathrm{kg}$ of imiglucerase every other week was initiated following diagnosis. Hemoglobin levels and
\end{abstract}

Correspondence to: Dr Yuji Oto, Department of Pediatrics, Saitama Medical Center, Dokkyo Medical University, 2-1-50 Minamikoshigaya, Koshigaya, Saitama 343-8555, Japan

E-mail: yuji-oto@dokkyomed.ac.jp

Abbreviations: ACE, angiotensin-converting enzyme; ERT, enzyme replacement therapy; ACP, acid phosphatase; GBA, glucocerebrosidase; GD, Gaucher disease; SD, standard deviation; TE, echo time; TR, repetition time

Key words: Gaucher disease, enzyme replacement therapy, glucocerebrosidase, pediatrics, L444P, F213I, Erlenmeyer flask deformity the platelet count gradually improved and normalized after two years. ACP and ACE levels, biomarkers of the progression of GD, also improved. Abdominal MRI at six months after the initiation of ERT revealed a decrease in the size of the liver and spleen, which normalized after 1 year. Conversely, MRI of the femora indicated no improvement in the high-intensity area within the diaphysis region for 10 years.

\section{Introduction}

Gaucher disease (GD) is an autosomal recessive lysosomal storage disorder caused by glucocerebrosidase (GBA) enzyme deficiency and is characterized by hepatosplenomegaly, anemia, thrombocytopenia, bone pain and growth retardation $(1,2)$. GD may be categorized into three subtypes depending on clinical symptoms: Non-neuronopathic (type 1), acute neuronopathic (type 2) and subacute neuronopathic (type 3) (3). Over 300 mutations of the GBA gene have been identified and there appear to be certain genotype-phenotype correlations (4). In Japan, the use of recombinant GBA (imiglucerase) was approved in 1998 (5). With respect to treatment, the development of enzyme replacement therapy (ERT) has markedly improved patient prognosis (6).

The prevalence associated with GD in Japan is lower than that in Western countries (1 per 330,000 vs. 1.16 per 100,000 live births, respectively) (7,8). In Japan, only 150 patients were estimated to have GD and the proportion of GD type 1 is rarer than that in other countries. Therefore, data on Japanese pediatric patients with GD type 1 are limited. The present study reported the case of a Japanese pediatric patient diagnosed with GD type 1, who presented with hepatosplenomegaly and thrombocytopenia at the age of 2 years, and was subsequently treated with ERT, which proved to be significantly effective for treating this condition.

\section{Case report}

A 2-year and 10-month-old female patient suffering from hepatosplenomegaly was referred to Dokkyo Medical University Saitama Medical Center (Saitama, Japan) in June 2009. The 
patient's medical history revealed no past episodes of fractures or convulsions and there were no signs of developmental delay. There was no family history of GD or Parkinson's disease. At 1 -year and 0 -month old, the patient started experiencing occasional petechiae with a bleeding tendency. On admission, the patient's body weight and length were $12.0 \mathrm{~kg}$ [-0.9 standard deviation (SD); normal range, $-2.0 \mathrm{SD}$ to $+2.0 \mathrm{SD}$ ] and $87.0 \mathrm{~cm}$ $(-2.1 \mathrm{SD})$, respectively. On physical examination, the patient was revealed to have severe hepatosplenomegaly, petechiae and purpura (Fig. 1). Neurologic examinations revealed no abnormalities. The patient's laboratory data are summarized in Table I. The patient had thrombocytopenia with slight anemia (platelets, $3.5 \times 10^{4} / \mu 1$; hemoglobin, $\left.10.4 \mathrm{~g} / \mathrm{dl}\right)$. Blood analysis revealed high levels of acid phosphatase (ACP) and angiotensin-converting enzyme (ACE). Abdominal MRI revealed huge hepatosplenomegaly (liver, 13.6x14.0 cm; spleen, $14.2 \times 6.7 \mathrm{~cm}$; Fig. 2). An Erlenmeyer flask deformity was seen on X-ray examination. MRI of the femora featured a high-intensity area within the diaphysis region (Fig. 2). Each MRI was collected on a Siemens Magnetom Avanto version VE11 (Siemens AG) and the software used to analyze the images was SYNAPSE VINCENT version 2.8.0 (Fujifilm Medical Co., Ltd). A bone marrow biopsy revealed the presence of Gaucher cells (Fig. 3). Enzymatic activity of leukocyte $\beta$-glucosidase, the measurement of which is necessary for the definitive diagnosis of Gaucher disease (2), had decreased to $186.7 \mathrm{nmol} / \mathrm{h} / \mathrm{mg}$ (reference range, $1,424.0-2,338.0 \mathrm{nmol} / \mathrm{h} / \mathrm{mg}$ ). Based on these results, the patient was clinically diagnosed with GD. GBA gene was analyzed using GBA sequence analysis. The analysis revealed the compound heterozygote mutation of F213I (c.754T>A) on exon 7 and L444P (c.1448T>C) on exon 11 by using Sanger sequencing (9).

At the age of 3.0 years, ERT was initiated for the patient, along with an intravenous infusion of $60 \mathrm{U} / \mathrm{kg}$ imiglucerase every other week. Hemoglobin levels and the platelet count were observed to improve gradually, and they normalized after two years (Fig. 4A). ACP and ACE levels, biomarkers of GD progression, were also indicated to improve (Fig. 4B). Abdominal MRI at six months after the initiation of ERT revealed a decrease in the size of the liver and spleen (liver: From $13.6 \times 14.0$ to $12.8 \times 8.6 \mathrm{~cm}$; spleen, from $14.2 \times 6.7$ to $13.5 \times 5.1 \mathrm{~cm}$ ), which also normalized after 1 year (Fig. 5A). Since then, follow-up abdominal MRIs were performed yearly to ensure early recognition of any changes (Fig. 5). Conversely, MRI of the femora indicated no improvement of the high-intensity area within the diaphysis region over 10 years (Fig. 5B). Although there was a certain degree of growth retardation [body weight $12.0 \mathrm{~kg}(-0.9 \mathrm{SD})$ and length $87.0 \mathrm{~cm}(-2.1 \mathrm{SD})$, normal body weight, $12.8 \pm 1.5 \mathrm{~kg}$; normal length, $90.9 \pm 3.3 \mathrm{~cm}$ )] at the initiation of ERT, this was observed to improve relatively early following initiation of ERT (Fig. 6).

\section{Discussion}

The present study described the case of a Japanese pediatric patient diagnosed with GD type 1 who significantly improved on ERT. In Japan, the prevalence of GD is lower compared with that in Western countries (8), and thus, limited data on Japanese pediatric patients with GD are currently available.

At 6 months following initiation of ERT, the liver and spleen of the patient had significantly decreased in size and
Table I. Laboratory findings prior to enzyme treatment therapy.

\begin{tabular}{lc}
\hline & $\begin{array}{c}\text { Normal } \\
\text { reference } \\
\text { Parameter }\end{array}$ Value \\
range/limit
\end{tabular}

\section{Hematology}

White blood cells $\left(\times 10^{3} / \mu 1\right)$

$6.2 \quad 4.0-12.0$

Hemoglobin $(\mathrm{g} / \mathrm{dl})$

$10.4 \quad 11.5-14.5$

Hematocrit (\%)

$32.9 \quad 33.0-45.0$

Platelets $\left(\mathrm{x} 10^{3} / \mu 1\right)$

$3.5 \quad 15.0-40.0$

Leukocyte count

Neutrophils (\%)

$49.0 \quad 38.0-68.0$

Lymphocytes (\%)

40.0

$27.0-47.0$

Monocytes (\%)

9.0

3.0-7.0

Blood chemistry

Total bilirubin (mg/dl)

Aspartate aminotransferase (U/l)

$0.84 \quad 0.40-1.00$

Alanine aminotransferase (U/l)

45

20-60

Alkaline phosphatase (U/l)

13

5-45

Gamma-glutamyl transpeptidase (U/l)

253

410-1,150

$5-32$

Total protein $(\mathrm{g} / \mathrm{dl})$

6.1-7.9

Albumin (g/dl)

6.7

$\begin{array}{cr}4.39 & 3.40-5.10 \\ 11.0 & 5.0-18.0\end{array}$

Blood urea nitrogen $(\mathrm{mg} / \mathrm{dl})$

Creatinine (mg/dl)

$0.17-0.37$

Sodium $(\mathrm{mEq} / \mathrm{l})$

0.20

134-143

Potassium (mEq/l)

3.3-4.6

Chloride (mEq/l)

98-106

Immunoglobulin $\mathrm{G}(\mathrm{mg} / \mathrm{dl})$

$345-1,236$

Coagulation

Prothrombin time activity (\%)

102.0

$70.0-120.0$

Activated partial thromboplastin

39.1

time (sec)

Fibrinogen (mg/dl)

$417 \quad 130-350$

Acid phosphatase (U/l)

134.2

$<14.4$

Angiotensin-converting-enzyme (U/ $\mu \mathrm{l})$

103.2

9.3-21.4

Leukocyte $\beta$-glucosidase (nmol/h/mg)

$186.7 \quad 1,424.0-2,338$

had normalized after 1 year of ERT. Hemoglobin levels and the platelet count improved gradually and had normalized after 2 years. ACP and ACE, which are commonly used for clinical diagnosis and assessment of treatment effectiveness, decreased gradually after initiation of ERT. Andersson et al (10) reported that long-term ERT for pediatric patients with GD type 1 was efficient. Anemia and thrombocytopenia, which were present in $>50 \%$ of patients at baseline, had resolved in $>95 \%$ of patients after 8 years of treatment. The response in the present case was consistent with this. Conversely, in the present case, chitotriosidase, chemokine $\mathrm{C}-\mathrm{C}$ motif ligand 18 (CCL18) and glucosylsphingosine could not be evaluated as good markers of disease progression prior to and during ERT, as the quantification of these markers was not commercially available in Japan. CCL18 and chitotriosidase are secreted by Gaucher cells and are markers for disease burden; consequently, 

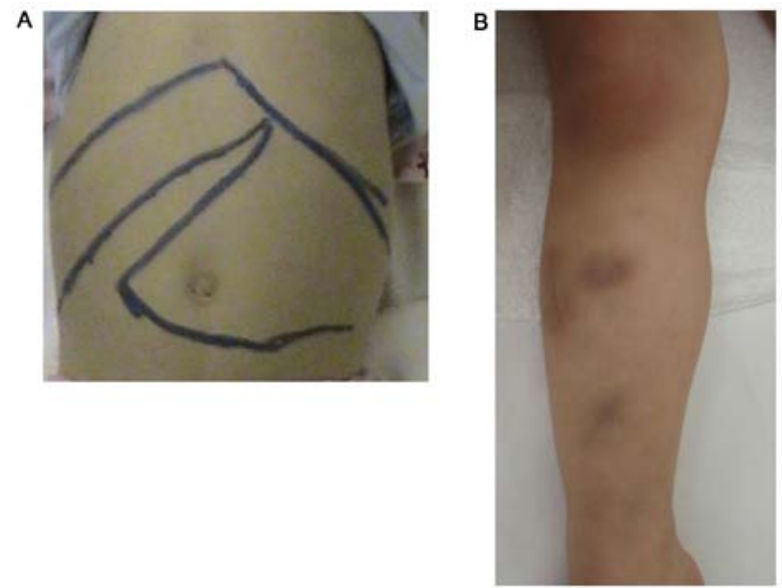

Figure 1. (A) Abdominal distension and (B) purpura on lower limbs before the start of enzyme replacement therapy.
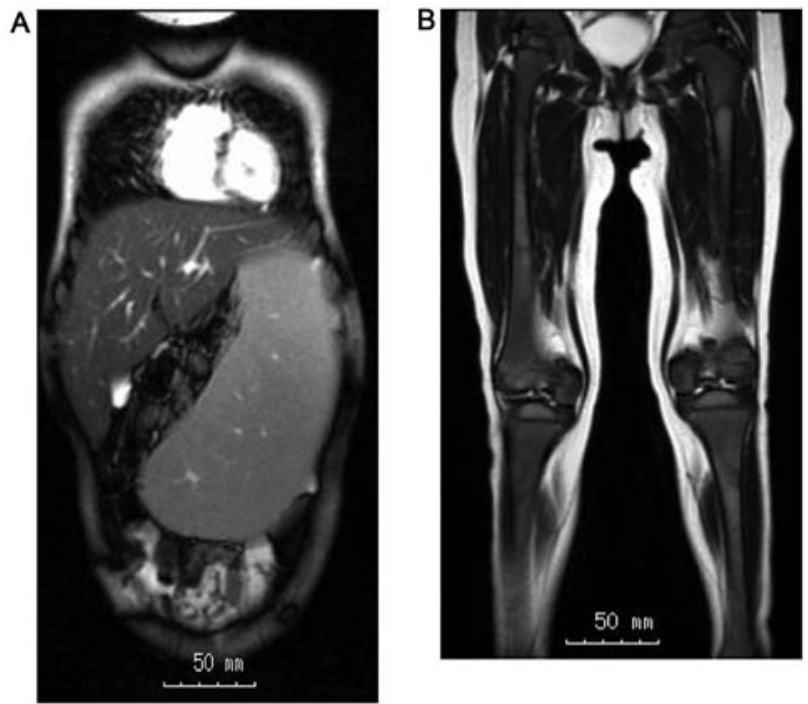

Figure 2.(A) Abdominal T1-weighted MRI,TR/TE3.7/1.85, and (B) T2-weighted MRI of the femora and tibia, TR/TE 5,000/105, prior to enzyme replacement therapy (scale bars, $50 \mathrm{~mm}$ ). TR, repetition time; TE, echo time.

plasma levels of these biomarkers are significantly increased in untreated patients with GD $(11,12)$. Glucosylsphingosine is also a sensitive and specific biomarker for primary diagnosis and follow-up monitoring of patients with GD (13). Increasing the accuracy of these biomarkers may spare patients from invasive examinations such as bone marrow biopsies to diagnose GD. A previous study indicated that long-term high-dose ERT (60 U/kg every 2 weeks) was required to obtain sufficient improvement to maintain health among pediatric patients with severe GD and ERT reduction (from 60 to 30 or $15 \mathrm{U} / \mathrm{kg}$ every 2 weeks) was associated with insufficient improvement of hemoglobin levels and the platelet count (14). ERT with imiglucerase was reported to achieve a dose-dependent improvement in hematological and visceral parameters in GD type 1 (15). Therefore, in the present case, long-term high-dose ERT (60 U/kg every 2 weeks) was maintained without any dose reduction.

Early manifestation of GD during childhood leads to growth retardation and a pathological growth pattern with tubulation of
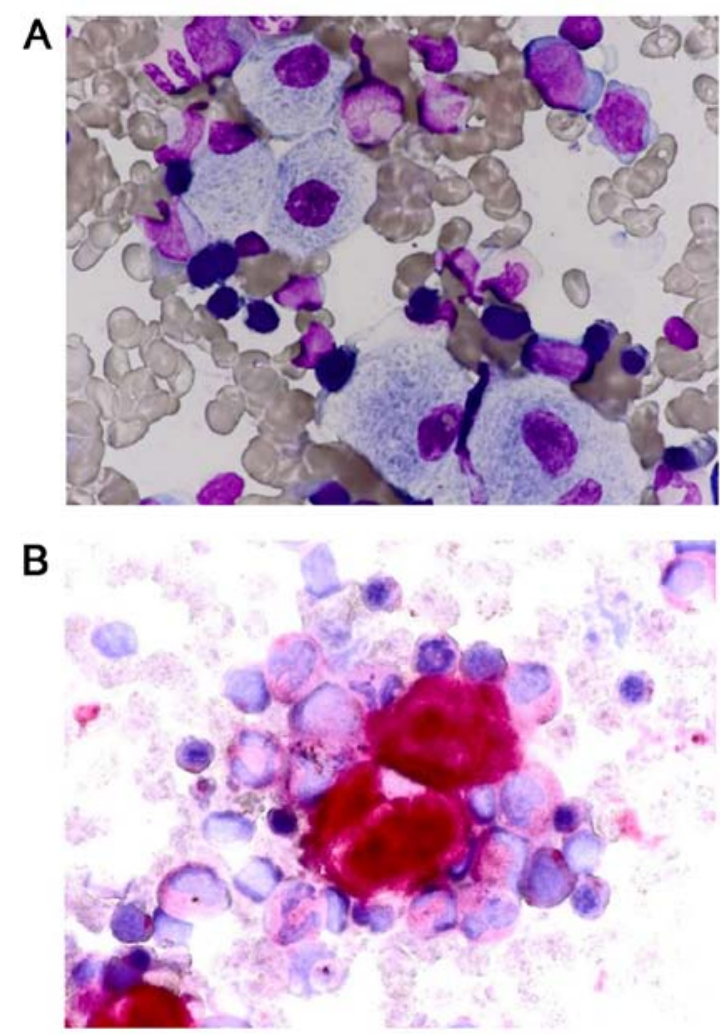

Figure 3. (A) Typical Gaucher cells with a 'wrinkled tissue pattern' on a bone marrow aspirate smear (magnification, x1,000; Wright-Giemsa stain). (B) The cytoplasm of Gaucher cells is well-stained with acid phosphatase stain (magnification, $\mathrm{x} 1,000$ ).

the metaphyseal area of the long bone, in particular, metaphysics of the distal femur and proximal tibia (16). Erlenmeyer flask deformity results from enlargement of the metaphyseal area and consequent absence of the typical concave diametaphyseal curve. Although it is generally held that ERT accelerates the growth rate (10), Mendelsohn et al (17) reported that ERT did not significantly impact the mean final height SD score. In their study, the effect of delayed puberty on stature was highlighted: Short stature during childhood is compensated by a long time of linear growth usually up to 15 years old, thereby enabling the patients to reach a normal body height in adulthood. In the present case, growth retardation was present before treatment, but it improved $\sim 2$ years following initiation of ERT. With respect to MRI, as bone fractures were never observed and bone pain was not reported (no lameness or complaints observed), it is unclear whether the high-intensity area within the diaphysis region of the femora on MRI had any pathological significance. The MRI of the femora did not improve in terms of intensity level within the diaphysis region 10 years after initiation of ERT. The MRI of the femora was evaluated by using the bone marrow signal intensity scores for the femurs $(18,19)$. The scores were 5 points prior to ERT and they did not improve for 3 years. At 4 years after initiation, the scores decreased to 4 points but did not change anymore thereafter. Certain studies suggested that ERT is effective for bone lesions (20-22), while others demonstrated limited effectiveness (23). The response to ERT for bone disease in adult patients with GD is considered much slower compared with pediatric patients. In the study by Sims et al (23), patients who received long-term high-dose 


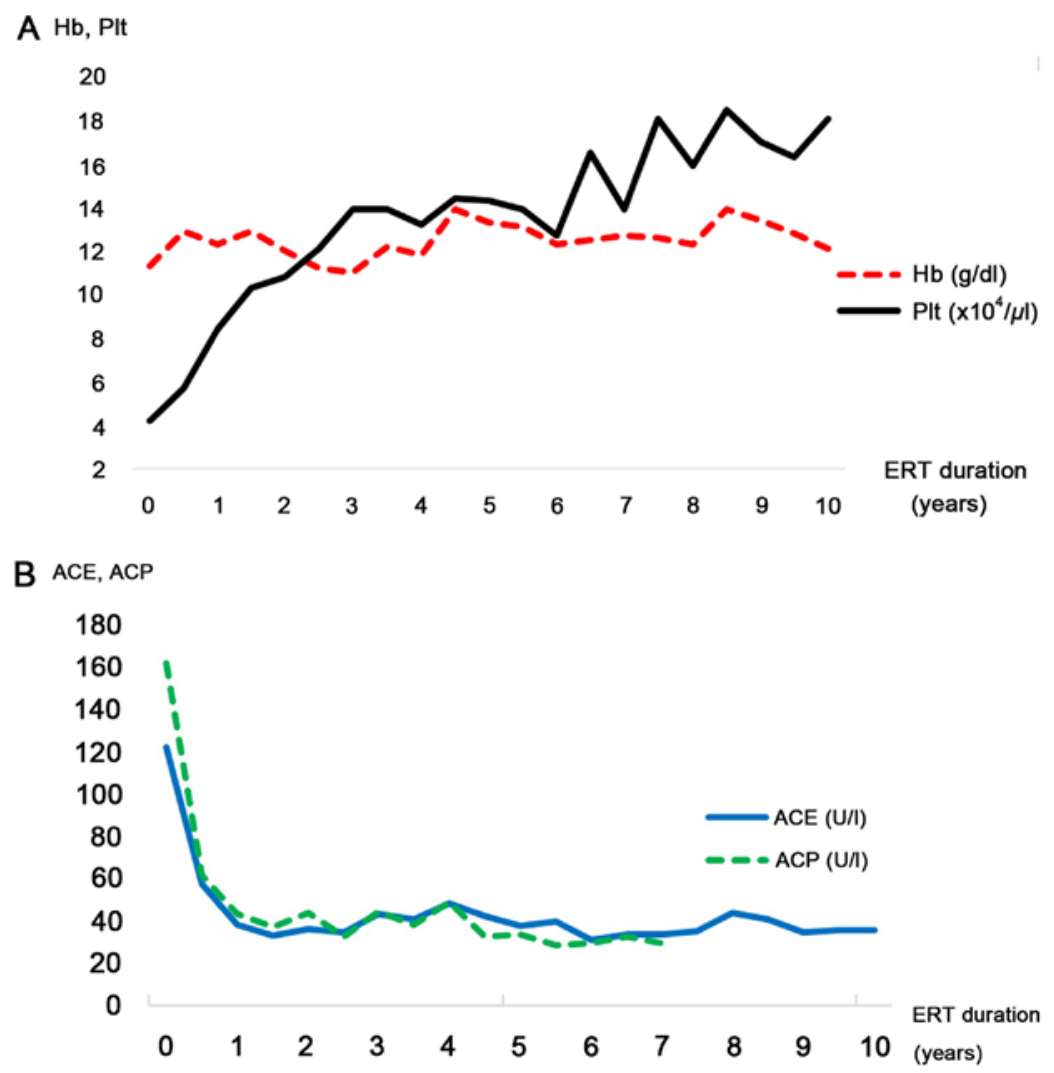

Figure 4. (A) Changes in Hb levels and Plt during the course of enzyme replacement therapy. (B) Changes in ACP and ACE during the course of ERT $\mathrm{Hb}$, hemoglobin; Plt, platelet count; ERT, enzyme replacement therapy; ACP, acid phosphatase; ACE, angiotensin-converting enzyme.
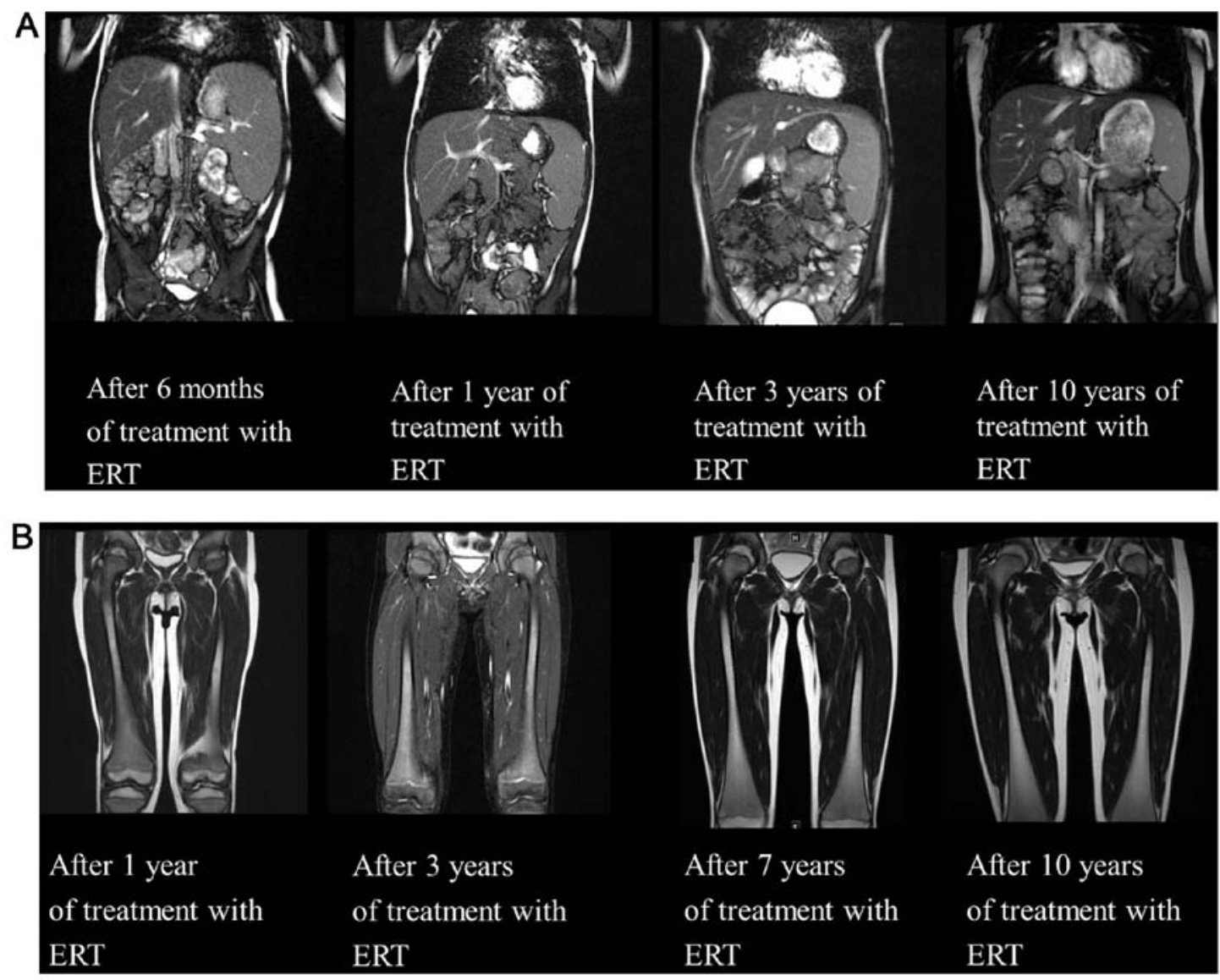

Figure 5. (A) Changes in abdominal T1-weighted MRI, TR/TE 3.7/1.85, after ERT. (B) Changes in T2-weighted MRI, TR/TE 5,000/105, of the femora after ERT. ERT, enzyme replacement therapy; TR, repetition time; TE, echo time. 


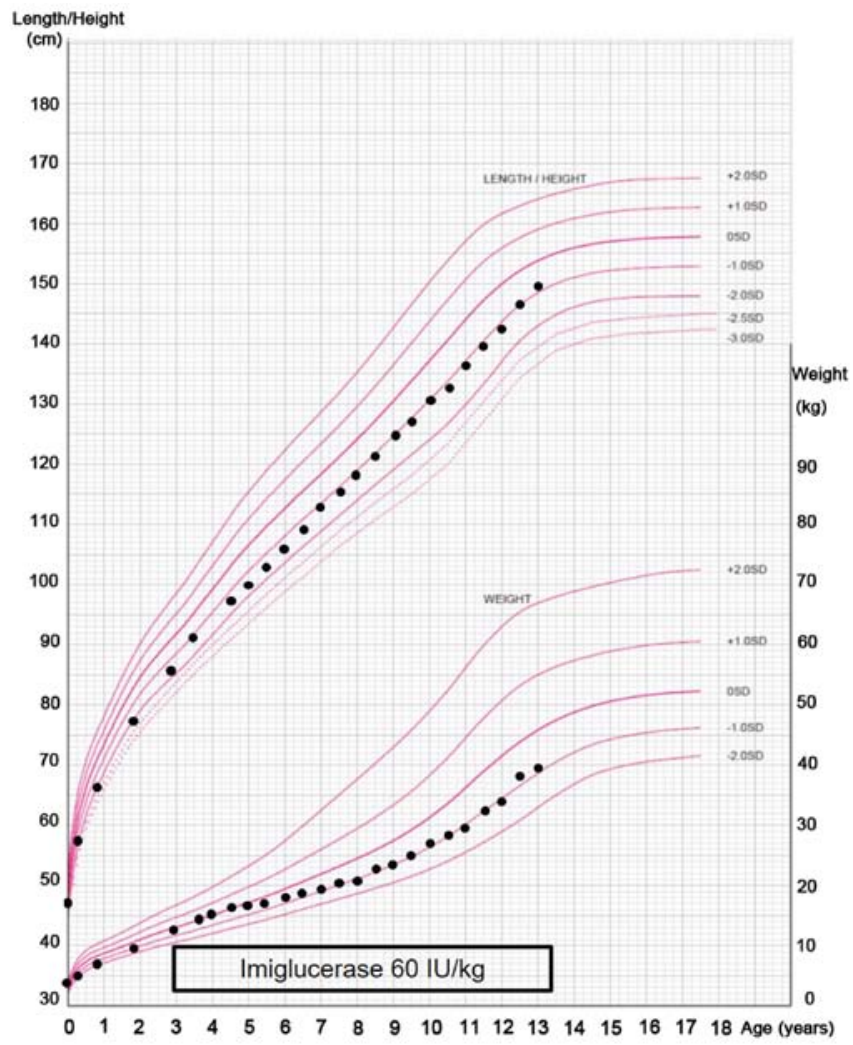

Figure 6. Cross-sectional Growth Chart for Girls (The 2000 National Survey on Preschool Children and School Health Statistics Research). The dotted lines of the -2.5 SD and -3.0 SD indicate the criteria for starting GH treatment for GH deficiency and achondroplasia, respectively, which are included in the Japanese Medical Aid Program for Specific Pediatric Chronic Diseases. The growth rate improved following the initiation of enzyme replacement therapy. SD, standard deviation; GH, growth hormone.

ERT exhibited improvement in bone pain and bone crisis However, bone pain was present in $73 \%$ of patients at baseline and $39 \%$ of patients still reported bone pain after 48 months of ERT. Furthermore, compared with the rapid reduction of bone pain and bone crisis, associated morphological changes were observed only after longer periods of therapy. According to one study, improvements on MRI were observed at the earliest after 2-3 years of treatment (24), whereas in another study, a decrease in bone marrow accumulation of glucocerebroside was apparent only after 3-4 years of ERT (25). The latter study indicated that generalized bone pain may be easily ameliorated by ERT, whereas pain attributable to focal, irreversible lesions tends to be more resistant (25). Furthermore, evidence from other lysosomal disorders may also support the role of inflammatory mediators in osteoarticular disease. In a similar manner to that in GD, bone complications in patients with mucopolysaccharidosis type 1 are less significantly modified by ERT with $\alpha$-L-iduronidase compared to that in other organs such as the liver and spleen (26). In general, the efficacy of ERT in bone and heart tissue is inferior in terms of uptake compared to that in the liver and spleen. Therefore, the effect on bone lesions may be delayed compared to that in the liver and spleen.

The mutation spectrum of GBA in the Japanese population is quite different from that in Western countries. For example, the L444P, N307S, 84GG, D409H, IVS2+1 and R463C mutations are commonly observed in Ashkenazi Jewish and non-Jewish populations in Israel (27). These six mutations account for $\sim 90$ and $\sim 75 \%$ of the total mutated alleles observed among Jewish and non-Jewish patients with GD, respectively (28). In particular, N307S is the most common mutation associated with GD type 1.In contrast, the N370S mutation have not been identified among Japanese patients. where the L444P and F213I alleles are the most prevalent (29). These two mutations account for 54\% of all mutations. The prevalence of L444P and F213I among Japanese patients is $\sim 43.6$ and $14.9 \%$, respectively, whereas in Ashkenazi Jewish patients, these mutations are relatively rare (9). Tajima et al (8) reported that L444P/L444P accounted for $61 \%$ of all genotypes in patients thought to have GD type 1 at diagnosis but who later developed GD type 3, followed by L444P/F213I (22\%) and F213I/F213I (11\%). L444P was associated with more severe disease and Japanese patients with GD tended to experience an earlier onset and progression with greater neurological involvement (30). In Japanese patients, the L444P/L444P genotype was more highly associated with GD type 3 as in Caucasian patients, compared with the association with GD type 1. F213I was also associated with neurologic symptoms, which was a unique mutation among patients with GD from Asia and it remains to be clarified how the F213I mutation affected the clinical course (8). In the case of the present study, symptoms were already present since the age of 1 year and the severity appeared to be high. However, the present case was clinically diagnosed with GD type 1 as there were no neurological complications. It may be reasoned that as the patient was young, neurological symptoms may not have developed and early initiation of ERT may have contributed to the prevention of these symptoms. Long-term neurological assessments as part of a follow-up are required to enable the evaluation of prognosis.

The prevalence of GD in Japan is much less compared to that in Western countries $(7,8)$, and it is not widely known among Japanese pediatricians and hematologists. Although $\sim 150$ patients with GD have been identified, there may be numerous undiagnosed patients with GD in Japan. In addition, the genetic distribution of Japanese patients with GD is completely different from that of Jewish patients and the frequency of unidentified mutations remains higher than that of Jewish patients with GD (28). Long-term follow-up studies and advancing technologies such as next-genome sequencing may determine the association between GD severity and novel mutations. Therefore, it is necessary to raise the awareness of GD among more general pediatricians and hematologists in Japan.

In conclusion, the present study reported the case of a Japanese pediatric patient with GD type 1 who, despite having a high disease severity, exhibited significant improvements on ERT over a 10-year duration.

\section{Acknowledgements}

The authors would like to thank Dr Toshiro Nagai (Department of Pediatrics, Nakagawa-no-sato Ryouiku Center, Saitama, Japan), Dr Yoshiko Abe (Department of Pediatrics, Abe Clinic, Saitama, Japan), Dr Takayoshi Tsuchiya (Department of Pediatrics, Sakurayama Pediatric Clinic, Kanagawa, Japan), Dr Yuriko Tanaka (Department of Pediatrics, Tanaka Clinic, Shizuoka, Japan) and Dr Kazuo Obata (Department of Pediatrics, Maple Lane Pediatrics, Hyogo, Japan) for their useful discussions. 


\section{Funding}

No funding was received.

\section{Availability of data and materials}

All data generated or analyzed during this study are included in this published article.

\section{Authors' contributions}

YO was the patient's doctor and wrote the manuscript. TI and SN made substantial contributions to the conception of the study and the acquisition of data. ST, HI, MS, AN, NM and TM made substantial contributions to the analysis and interpretation of data. HI analyzed enzymatic activity and the GBA gene. All of the authors were involved in writing the manuscript and revised the manuscript critically for important intellectual content, and read and approved the final manuscript.

\section{Ethics approval and consent to participate}

The study was approved by the Ethics Committee of Dokkyo Medical University Saitama Medical Center (Koshigaya, Japan; no. 2025). Formal written informed consent was obtained from the patient and the parents of the patient.

\section{Patient consent for publication}

The authors received formal written informed consent from the patient and the parents of the patient approving the publication of these data.

\section{Competing interests}

The authors declare that they have no competing interests.

\section{References}

1. Baris HN, Cohen IJ and Mistry PK: Gaucher disease: The metabolic defect, pathophysiology, phenotypes and natural history. Pediatr Endocrinol Rev 12 (Suppl 1): 72-81, 2014.

2. Cox TM and Schofield JP: Gaucher's disease: Clinical features and natural history. Baillieres Clin Haematol 10: 657-689, 1997.

3. Thomas AS, Mehta A and Hughes DA: Gaucher disease: Haematological presentations and complications. $\mathrm{Br} \mathrm{J}$ Haematol 165: 427-440, 2014.

4. Hruska KS, La Marca ME, Scott CR and Sidransky E: Gaucher disease: mutation and polymorphism spectrum in the glucocerebrosidase gene (GBA). Hum Mutat 29: 567-583, 2008.

5. Eto Y, Ida H, Ohashi T, Okuyama T, Sakai N, Takayanagi M, Narita A and Nanba E (eds). Gaucher Disease Update. 1st edition. Shindantochiryousha, pp91-92, 2016 (In Japanese)

6. Starzyk K, Richards S, Yee J, Smith SE and Kingma W: The long-term international safety experience of imiglucerase therapy for Gaucher disease. Mol Genet Metab 90: 157-163, 2007.

7. Poorthuis BJ, Wevers RA, Kleijer WJ, Groener JE, de Jong JG, van Weely S, Niezen-Koning KE and van Diggelen OP: The frequency of lysosomal storage diseases in The Netherlands. Hum Genet 105: 151-156, 1999.

8. Tajima A, Yokoi T, Ariga M, Ito T, Kaneshiro E, Eto Y and Ida H: Clinical and genetic study of Japanese patients with type 3 Gaucher disease. Mol Genet Metab 97: 272-277, 2009.

9. Ida H, Rennert OM, Kawame H, Maekawa K and Eto Y: Mutation prevalence among 47 unrelated Japanese patients with Gaucher disease: Identification of four novel mutations. J Inherit Metab Dis 20: 67-73, 1997.
10. Andersson H, Kaplan P, Kacena K and Yee J: Eight-year clinical outcomes of long-term enzyme replacement therapy for 884 children with Gaucher disease type 1. Pediatrics 122: 1182-1190, 2008.

11. Boot RG, Verhoek M, de Fost M, Hollak CE, Maas M, Bleijlevens B, van Breemen MJ, van Meurs M, Boven LA, Laman JD, et al: Marked elevation of the chemokine CCL18/PARC in Gaucher disease: A novel surrogate marker for assessing therapeutic intervention. Blood 103: 33-39, 2004.

12. Hollak CE, van Weely S, van Oers MH and Aerts JM: Marked elevation of plasma chitotriosidase activity. A novel hallmark of Gaucher disease. J Clin Invest 93: 1288-1292, 1994.

13. Arkadir D, Dinur T, Revel-Vilk S, Becker Cohen M, Cozma C, Hovakimyan M, Eichler S, Rolfs A and Zimran A: Glucosylsphingosine is a reliable response biomarker in Gaucher disease. Am J Hematol 93: E140-E142, 2018.

14. Ida H, Rennert OM, Kobayashi M and Eto Y: Effects of enzyme replacement therapy in thirteen Japanese paediatric patients with Gaucher disease. Eur J Pediatr 160: 21-25, 2001.

15. Grabowski GA, Kacena K, Cole JA, Hollak CE, Zhang L, Yee J, Mistry PK, Zimran A, Charrow J and vom Dahl S: Dose-response relationships for enzyme replacement therapy with imiglucerase/ alglucerase in patients with Gaucher disease type 1. Genet Med 11: 92-100, 2009.

16. Wenstrup RJ, Roca-Espiau M, Weinreb NJ and Bembi B: Skeletal aspects of Gaucher disease: A review. Br J Radiol 75 (Suppl 1): A2-A12, 2002.

17. Mendelsohn E, Meir A, Abrahamov A, Elstein D, Zimran A and Levy-Khademi F: Growth and final height of children with Gaucher disease: A 15-year follow-up at an Israeli Gaucher center. Blood Cells Mol Dis 68: 97-99, 2018.

18. Robertson PL, Maas M and Goldblatt J: Semiquantitative assessment of skeletal response to enzyme replacement therapy for Gaucher's disease using the bone marrow burden score. AJR Am J Roentgenol 188: 1521-1528, 2007.

19. Vom Dahl S, Poll L, Di Rocco M, Ciana G, Denes C, Mariani G and Maas M: Evidence-based recommendations for monitoring bone disease and the response to enzyme replacement therapy in Gaucher patients. Curr Med Res Opin 22: 1045-1064, 2006.

20. Hughes D, Mikosch P, Belmatoug N, Carubbi F, Cox T, Goker-Alpan O, Kindmark A, Mistry P, Poll L, Weinreb N, et al: Gaucher Disease in Bone: From Pathophysiology to Practice. J Bone Miner Res 34: 996-1013, 2019.

21. Weinreb NJ, Goldblatt J, Villalobos J, Charrow J, Cole JA, Kerstenetzky M, vom Dahl S and Hollak C: Long-term clinical outcomes in type 1 Gaucher disease following 10 years of imiglucerase treatment. J Inherit Metab Dis 36: 543-553, 2013.

22. Charrow J, Dulisse B, Grabowski GA and Weinreb NJ: The effect of enzyme replacement therapy on bone crisis and bone pain in patients with type 1 Gaucher disease. Clin Genet 71: 205-211,2007.

23. Sims KB, Pastores GM, Weinreb NJ, Barranger J, Rosenbloom BE, Packman S, Kaplan P, Mankin H, Xavier R, Angell J, et al: Improvement of bone disease by imiglucerase (Cerezyme) therapy in patients with skeletal manifestations of type 1 Gaucher disease: Results of a 48-month longitudinal cohort study. Clin Genet 73: 430-440, 2008.

24. Poll LW, Koch JA, vom Dahl S, Willers R, Scherer A, Boerner D, Niederau C, Häussinger D and Mödder U: Magnetic resonance imaging of bone marrow changes in Gaucher disease during enzyme replacement therapy: First German long-term results. Skeletal Radiol 30: 496-503, 2001.

25. Poll LW, Maas M, Terk MR, Roca-Espiau M, Bembi B, Ciana G and Weinreb NJ: Response of Gaucher bone disease to enzyme replacement therapy. Br J Radiol 75 (Suppl 1): A25-A36, 2002.

26. Simonaro CM, Haskins ME and Schuchman EH: Articular chondrocytes from animals with a dermatan sulfate storage disease undergo a high rate of apoptosis and release nitric oxide and inflammatory cytokines: A possible mechanism underlying degenerative joint disease in the mucopolysaccharidoses. Lab Invest 81: 1319-1328, 2001.

27. Horowitz M, Tzuri G, Eyal N, Berebi A, Kolodny EH, Brady RO, Barton NW, Abrahamov A and Zimran A: Prevalence of nine mutations among Jewish and non-Jewish Gaucher disease patients. Am J Hum Genet 53: 921-930, 1993.

28. Beutler E, Gelbart T and West C: Identification of six new Gaucher disease mutations. Genomics 15: 203-205, 1993.

29. Ida H, Rennert OM, Ito T, Maekawa K and Eto Y: Type 1 Gaucher disease: Phenotypic expression and natural history in Japanese patients. Blood Cells Mol Dis 24: 73-81, 1998.

30. Ida H, Owen MR, Iwasawa K, Kobayashi M and Eto Y: Clinical and genetic studies of Japanese homozygotes for the Gaucher disease L444P mutation. J Hum Genet 105: 120-126, 1999. 